Research

Open Access

\title{
Acute kidney injury is common, parallels organ dysfunction or failure, and carries appreciable mortality in patients with major burns: a prospective exploratory cohort study
}

\author{
I Steinvall1,2, Z Bak ${ }^{1,3}$ and F Sjoberg ${ }^{1,2,3}$
}

\author{
1The Burn Unit, Department of Hand and Plastic Surgery, Linköping University Hospital, Garnisonsvägen, Linköping, 58185, Sweden \\ ${ }^{2}$ Department of Clinical and Experimental Medicine, Faculty of Health Sciences, Linköping University Hospital, Garnisonsvägen, Linköping, 58185, \\ Sweden \\ 3Department of Anesthesia and Intensive Care, Linköping University Hospital, Garnisonsvägen, Linköping, 58185, Sweden \\ Corresponding author: I Steinvall, ingrid.steinvall@lio.se
}

Received: 7 Jul 2008 Revisions requested: 28 Aug 2008 Revisions received: 25 Sep 2008 Accepted: 10 Oct 2008 Published: 10 Oct 2008

Critical Care 2008, 12:R124 (doi:10.1186/cc7032)

This article is online at: http://ccforum.com/content/12/5/R124

(c) 2008 Steinvall et al.; licensee BioMed Central Ltd.

This is an open access article distributed under the terms of the Creative Commons Attribution License (http://creativecommons.org/licenses/by/2.0), which permits unrestricted use, distribution, and reproduction in any medium, provided the original work is properly cited.

\begin{abstract}
Introduction The purpose of this study was to determine the incidence, time course, and outcome of acute kidney injury after major burns and to evaluate the impact of possible predisposing factors (age, gender, and depth and extent of injury) and the relation to other dysfunctioning organs and sepsis.

Method We performed an explorative cohort study on patients with a TBSA\% (percentage burned of total body surface area) of $20 \%$ or more who were admitted to a national burn centre. Acute kidney injury was classified according to the international consensus classification of RIFLE (Risk, Injury, Failure, Loss of kidney function, and End-stage kidney disease). Prospectively collected clinical and laboratory data were used for assessing organ dysfunction, systemic inflammatory response, and sepsis.

Results The incidence of acute kidney injury among major burns was 0.11 per 100,000 people per year. Of 127 patients, 31 (24\%) developed acute kidney injury (12\% Risk, $8 \%$ Injury, and $5 \%$ Failure). Mean age was 40.6 years ( $95 \%$ confidence interval [Cl] 36.7 to 44.5$)$, TBSA $\%$ was $38.6 \%(95 \% \mathrm{Cl} 35.5 \%$ to $41.6 \%$ ), and $25 \%$ were women. Mortality was $14 \%$ and
\end{abstract}

increased with increasing RIFLE class (7\% normal, 13\% Risk, $40 \%$ Injury, and $83 \%$ Failure). Renal dysfunction occurred within 7 days in 55\% of the patients and recovered among all survivors. Age, TBSA\%, and extent of full thickness burns were higher among the patients who developed acute kidney injury. Pulmonary dysfunction and systemic inflammatory response syndrome were present in all of the patients with acute kidney injury and developed before the acute kidney injury. Sepsis was a possible aggravating factor in acute kidney injury in $48 \%$. Extensive deep burns (25\% or more full thickness burn) increased the risk for developing acute kidney injury early (risk ratio 2.25$)$.

Conclusions Acute kidney injury is common, develops soon after the burn, and parallels other dysfunctioning organs. Although acute kidney injury recovered in all survivors, in higher acute kidney injury groups, together with cardiovascular dysfunction, it correlated with mortality.

\section{Introduction}

Renal failure is a feared complication of critical illness and is also often an early sign of multiple organ dysfunction, which complicates the care of critically ill patients [1-4]. In modern burn care, in which most patients now survive early resuscitation, multiple organ failure is the most common cause of death.
In the largest database of patients with burn injuries, the American Burn Association burn registry, records of the cause of mortality indicate that $49 \%$ of the non-survivors died of organ failure [5]. The incidence of acute kidney injury (AKI) among burned patients varied from less than $1 \%$ to $36 \%$, depending on the population studied and the criteria used for

AKI: acute kidney injury; BW: body weight; Cl: confidence interval; CT: computed tomography; $\mathrm{FiO}_{2}$ : fraction of inspired oxygen; FTB: full thickness burn; ICU: intensive care unit; $\mathrm{PaO}_{2}$ : arterial partial pressure of oxygen; RIFLE: Risk, Injury, Failure, Loss of kidney function, and End-stage kidney disease; SIRS: systemic inflammatory response syndrome; SOFA: sequential organ failure assessment; TBSA\%: percentage burned of total body surface area. 
Critical Care Vol 12 No 5 Steinvall et al.

Table 1

Incidence, mortality, and criteria for acute kidney injury in patients with burns

\begin{tabular}{|c|c|c|c|c|c|}
\hline Reference & Year & Years of study; population & AKI & AKI mortality & Criterion of $\mathrm{AKI}$ \\
\hline Davies, et al. [8] & 1979 & $\begin{array}{l}1958-1979 ;>1,064 \text { patients } \\
\text { admitted }\end{array}$ & $28(<2.6 \%)$ & $24(86 \%)$ & Renal replacement therapy \\
\hline Davies, et al. [9] & 1994 & $1991 ; 18$ burn units & $15(<1 \%)$ & $12(80 \%)$ & Renal replacement therapy \\
\hline Leblanc, et al. [10] & 1997 & $\begin{array}{l}\text { 1987-1994; } 970 \text { patients } \\
\text { admitted }\end{array}$ & $16(1.6 \%)$ & $13(82 \%)$ & Renal replacement therapy \\
\hline Holm, et al. [11] & 1999 & $\begin{array}{l}\text { 1994-1998; } 328 \text { patients, } \\
34 \% \text { TBSA } \%\end{array}$ & $48(15 \%)$ & $41(85 \%)$ & Renal replacement therapy \\
\hline Tremblay, et al. [12] & 2000 & $\begin{array}{l}\text { 1995-1998; } 353 \text { patients } \\
\text { admitted }\end{array}$ & $12(3.4 \%)$ & $6(50 \%)$ & Renal replacement therapy \\
\hline \multirow[t]{2}{*}{ Schiavon, et al. [13] } & 1988 & $\begin{array}{l}1988 ; 20 \text { patients, } 44 \% \\
\text { TBSA } \%\end{array}$ & $4(20 \%)$ & $4(100 \%)$ & $\begin{array}{l}\text { Serum creatinine raised }>133 \mu \mathrm{mol} / \mathrm{L} \text { above } \\
\text { value on admission }\end{array}$ \\
\hline & & & 0 & & Renal replacement therapy \\
\hline \multirow[t]{2}{*}{ Saffle, et al. [7] } & 1993 & $\begin{array}{l}\text { 1987-1990; } 529 \text { patients, } \\
\text { 16\% TBSA } \%\end{array}$ & $50(10 \%)$ & $23(46 \%)$ & $\begin{array}{l}\text { Thermal Injury Organ Failure Score (moderate: } \\
\text { serum creatinine }>222 \mu \mathrm{mol} / \mathrm{L} \text { ) }\end{array}$ \\
\hline & & & $4(0.8 \%)$ & $4(100 \%)$ & Renal replacement therapy \\
\hline Sheridan, et al. [14] & 1998 & $\begin{array}{l}\text { 1989-1994; } 56 \text { patients who } \\
\text { died }\end{array}$ & $37(68 \%)$ & - & $\begin{array}{l}\text { Serum BUN } \geq 100 \text { and creatinine } \geq 3.5 \text { or urine } \\
\text { output } \leq 500 \mathrm{~mL} / \text { day }\end{array}$ \\
\hline \multirow[t]{2}{*}{ Jeschke, et al. [15] } & 1998 & $\begin{array}{l}\text { 1966-1997; 5,000 children } \\
\text { admitted }\end{array}$ & $60(1.2 \%)$ & $44(73 \%)$ & $\begin{array}{l}\text { Oliguria }(<0.5 \mathrm{~mL} / \mathrm{kg} \text { per hour for }>36 \text { hours }) \\
\text { serum urea nitrogen/creatinine ratio }<20 \text {, serum } \\
\text { creatinine }>177 \mu \mathrm{mol} / \mathrm{L}\end{array}$ \\
\hline & & & $34(0.7)$ & $28(82 \%)$ & Renal replacement therapy \\
\hline \multirow[t]{2}{*}{ Chrysopoulo, et al. [16] } & 1999 & $\begin{array}{l}1981-1998 ; 1,404 \text { patients, } \\
\text { TBSA } \%>30 \%\end{array}$ & $76(5.4 \%)$ & $67(88 \%)$ & $\begin{array}{l}\text { Three of these four: oliguria }(<350 \mathrm{~mL} / 36 \text { hours }) \text {, } \\
\text { BUN/creatinine ratio }<20 \text {, serum creatinine }>177 \\
\mu \mathrm{mol} / \mathrm{L} \text {, and dialysis }\end{array}$ \\
\hline & & & $67(4.8 \%)$ & $61(91 \%)$ & Renal replacement therapy \\
\hline \multirow[t]{2}{*}{ Kim, et al. [17] } & 2003 & $\begin{array}{l}2000 ; 147 \text { patients, } 60 \% \\
\text { TBSA } \%\end{array}$ & $28(19 \%)$ & $28(100 \%)$ & Serum creatinine $>177 \mu \mathrm{mol} / \mathrm{L}$ \\
\hline & & & $3(2.0 \%)$ & $3(100 \%)$ & Renal replacement therapy \\
\hline \multirow[t]{2}{*}{$\begin{array}{l}\text { Mustonen and Vuola } \\
\text { [22] }\end{array}$} & 2008 & $\begin{array}{l}\text { 1988-2001; } 238 \text { patients, } \\
31 \% \text { TBSA } \%\end{array}$ & $93(39.1 \%)$ & $41(44 \%)$ & Serum creatinine $>120 \mu \mathrm{mol} / \mathrm{L}$ \\
\hline & & & $32(13 \%)$ & $20(62 \%)$ & Renal replacement therapy \\
\hline Cumming, et al. [6] & 2001 & $\begin{array}{l}1998-1999 ; 85 \text { patients, 30\% } \\
\text { TBSA\% }\end{array}$ & $3(3.5 \%)$ & & MODS (3-4: serum creatinine $>350 \mu \mathrm{mol} / \mathrm{L})$ \\
\hline Cooper, et al. [18] & 2006 & $\begin{array}{l}1999-2001 ; 42 \text { patients, } 35 \% \\
\text { TBSA\% }\end{array}$ & $3(7.1 \%)$ & & $\begin{array}{l}\text { MODS (3-4: serum creatinine }>350 \mu \mathrm{mol} / \mathrm{L} \text { ) or } \\
\text { oliguria }\end{array}$ \\
\hline \multirow[t]{2}{*}{ Coca, et al. [19] } & 2007 & $\begin{array}{l}\text { 1998-2003; } 304 \text { patients, } \\
\text { 27\% TBSA\% }\end{array}$ & $81(27 \%)$ & $23(28 \%)$ & RIFLE \\
\hline & & & & $(73 \%)$ & Renal replacement therapy \\
\hline \multirow[t]{2}{*}{ Lopes, et al. [20] } & 2007 & $\begin{array}{l}\text { 2004-2006; } 126 \text { patients, } \\
24 \% \text { TBSA } \%\end{array}$ & $45(36 \%)$ & $21(47 \%)$ & RIFLE \\
\hline & & & $11(8.7 \%)$ & & Renal replacement therapy \\
\hline
\end{tabular}

The table shows number of patients who had acute kidney injury (AKI) according to the criteria in the rightmost column; the percentage is the incidence of AKI among the study population. AKI mortality is the number of patients who died among those with AKI, with the percentage referring to mortality among the AKI patients. When available, incidence and outcome of renal replacement therapy are shown in the table, together with the result from the primary AKI criteria. Percentage burned of total body surface area (TBSA\%) is the mean of the study group. When a TBSA\% limit for inclusion was reported instead, it is shown in this table as 'TBSA\% $>\%$ '. BUN, blood urea nitrogen; MODS, Multiple Organ Dysfunction Score; RIFLE, the increasing severity classes Risk, Injury, and Failure and the two outcome classes Loss, and End-stage renal disease. 
classification (Table 1). Another shortcoming was that most studies were carried out retrospectively. Of the studies that claimed to collect data prospectively, not all measures of organ failure were collected according to a true prospective protocol $[6,7]$. It is therefore obvious that there is a risk that organ dysfunction may have been overlooked or missed. The mortality among burned patients who developed AKI was between $28 \%$ and $100 \%$ and was $50 \%$ to $100 \%$ among those who were treated with renal replacement therapy. The reported incidence of renal replacement therapy varied from $0.7 \%$ to $14.6 \%$ (Table 1 ) [6-22].

It is evident therefore that the definitions, protocols, and collection of data vary considerably among different studies, which makes it difficult to compare results. For the present investigation, we chose to use the RIFLE (Risk, Injury, Failure, Loss of kidney function, and End-stage kidney disease) classification, which was developed recently by the Acute Dialysis Quality Initiative Group and published as a consensus definition of acute renal failure in critical care [23]. We set up the following hypotheses about the present study: first, AKI is common and develops soon after a major burn. Second, it is affected by factors that are described as important for the development of multiple organ dysfunction or failure in patients with burns such as age $[6,7,24]$, percentage burned of total body surface area (TBSA\%) [6,7,24], and sepsis $[11,12,15,16,19]$. As AKI develops together with failure of other organs $[7,11,14]$ and outcome depends on the number and degree of failing organs $[6,7,24]$, assessment of organ failures was made in parallel with the sequential organ failure assessment (SOFA) [25], which is well documented and validated [26-28].

\section{Materials and methods}

The burn centre serves 3.3 million inhabitants for referral of patients who require specialist burn care (major burns) from the southern part of Sweden. Consecutive patients with a TBSA $\%$ of $20 \%$ or more, who were admitted between 1997 and 2005 (8.5 years), were studied. Clinical and laboratory data, collected according to a preset protocol, were recorded during the study period. Patients who died within the first 2 days, including those from whom treatment was withheld or withdrawn early, were excluded. Patients with superficial burns that did not require operation and whose time in hospital was short ( 1 to 7 days) were also excluded (Figure 1). The local ethics committee at Linköping University Hospital waived the need for their approval for descriptive and explorative studies that do not include any procedures that are not considered as ordinary burn care.

\section{Treatment of burns and supportive intensive care}

Ringer's acetate was used for fluid resuscitation in volumes according to the Parkland formula $(4 \mathrm{~mL} / \mathrm{kg}$ body weight [BW]/TBSA\%) [29-31], with adjustments for individual variations in hemodynamic variables, aiming at least for a mean
Figure 1

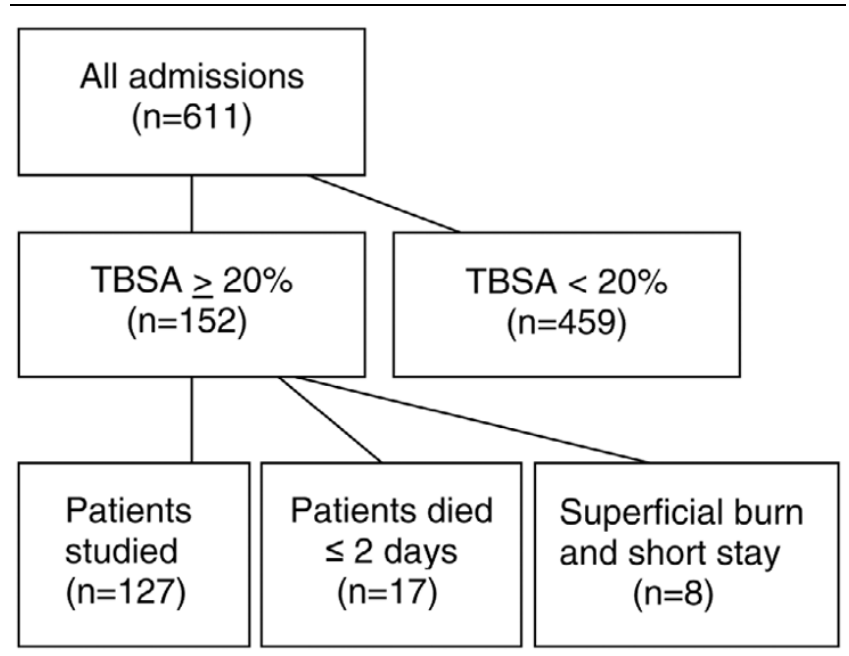

Algorithm showing selection of patients. TBSA, percentage burned of total body surface area.

arterial pressure of $70 \mathrm{~mm} \mathrm{Hg}$ and a urine output of $1 \mathrm{~mL} / \mathrm{kg}$ BW per hour. When fluid volume substitution alone was insufficient to maintain central hemodynamics, adrenergic drugs (dobutamine and norepinephrine) were used. Renal replacement therapy was considered when the plasma creatinine concentration exceeded $300 \mu \mathrm{mol} / \mathrm{L}$, together with oliguria or anuria.

Excision and grafting operations were done within 24 to 48 hours. Patients who did not seem to have deep burns at primary examination were re-evaluated daily and operated on if full thickness burns (FTBs) were identified. Wounds were covered by autologous grafts when available or, in extensive burns, either by heterologous grafts for temporary cover or (in special cases) by cultured keratinocytes. Operations were repeated when donor sites again became available. Silver sulfadiazine (Flamazine ${ }^{\circledR}$; Smith \& Nephew, Hull, UK) was applied to both grafted and non-grafted wounds. Infection control was managed in collaboration with the university hospital infection specialists.

Ventilation was pressure-controlled (Siemens $900 \mathrm{C}$ or Siemens 300 A; Siemens, Solna, Sweden) with tidal volumes of 6 to $8 \mathrm{~mL} / \mathrm{kg} \mathrm{BW}$, a positive end-expiratory pressure of at least $5 \mathrm{~cm} \mathrm{H}_{2} \mathrm{O}$, and aiming at low ventilatory plateau pressures (of less than $35 \mathrm{~cm} \mathrm{H}_{2} \mathrm{O}$ ) [32]. Nutrition was provided enterally from day 1 , pain was controlled by continuous infusions of opioids, and sedation was carried out by infusion of benzodiazepines.

\section{Classification of acute kidney injury}

AKI was classified by a dynamic classification scheme with three levels for acute renal dysfunction: Risk, Injury, and Failure and two clinical outcomes, Loss of kidney function and Endstage kidney disease (RIFLE) [23]. It is based on how the 
plasma creatinine concentration is increased compared with the baseline value of the individual patient, reduced urinary output, and the need for renal replacement therapy. The earliest available plasma creatinine concentration measurement was used as the baseline. Plasma creatinine concentrations from the first week, and thereafter the highest value weekly, were used for RIFLE classification and assessment of renal recovery.

\section{Classification of organ dysfunction}

SOFA score was recorded at admission and at least three times a week. SOFA score is based on the assessment of six organ dimensions: (a) renal: plasma creatinine concentration or urine output, (b) respiratory: arterial partial pressure of oxygen/fraction of inspired oxygen $\left(\mathrm{PaO}_{2} / \mathrm{FiO}_{2}\right)$ ratio, (c) cardiovascular: hypotension or need for adrenergic agents, (d) coagulation: platelet count, and (e) hepatic: plasma bilirubin concentration. The neurological part of SOFA ( $f$ ) was left out because of the difficulties in assessing the Glasgow coma score in sedated patients. Maximum SOFA is the maximum score value from each organ score, regardless of date [27]. For this study, multiple organ failure was defined as 3 to 4 score points in two or more organ dimensions of the SOFA score [26]. Blood samples were drawn at the time of admission and at least three times a week in accordance with the Burn Unit protocol for major burns. Admission values were used to compare baseline values among groups; the worst value of each patient during the first week was used to analyse factors of importance for AKI. The worst overall value was used to analyse factors of importance for mortality, and the worst value of each patient each week was used to calculate the maximum SOFA score and the descriptive figures of the time course. Laboratory variables were analysed by routine methods and data were stored in the countywide database of the laboratory. Sepsis and systemic inflammatory response syndrome (SIRS) were classified according to the American College of Chest Physicians/Society of Critical Care Medicine Consensus Conference [33].

\section{Additional data acquisition}

All patients were recorded prospectively in the Linköping Burn Unit Database. At admission, extent (TBSA\%) and depth (FTB\%) of injury were recorded together with patient characteristics such as age and gender [34]. Daily recordings of care and treatment included variables such as requirement for dialysis, mechanical ventilation, and adrenergic agents. Data regarding the giving of nephrotoxic antibiotics (vancomycin, aminoglycosides, and amphotericin B) and exposure to intravenous contrast (computed tomography [CT] scans) were extracted from medication charts.

\section{Statistics}

Data were analysed with STATISTICA 7 (StatSoft, Inc., Tulsa, OK, USA) and presented as mean and 95\% confidence interval $(\mathrm{Cl})$. The differences in baseline characteristics and out- come among patients with and without $\mathrm{AKI}$ and the differences in mean values between those who developed AKI early and late were analysed using Student $t$ test for continuous data and contingency tables with Pearson chi-square test for categorical variables. Analysis of covariance was used adjusting laboratory data for age and TBSA\%. The Tukey unequal N HSD (honest significant difference test for unequal sample sizes) was used as a post hoc test. The difference in progress time was analysed by using Student $t$ test for dependent samples. One-way analysis of variance, for continuous data, and contingency tables with Pearson chi-square test for categorical variables were used to analyse the differences in baseline characteristics and outcome among the patients who developed AKI, grouped in RIFLE classes. Continuous variables were arbitrarily categorised when exploring risk factors for the development of early and late AKI with odds ratios: cutoff age of 60 years, FTB\% of $25 \%$, TBSA\% of $50 \%$, and reaching the level for Risk within the first 7 days for early AKI.

\section{Results \\ Incidence}

The incidence of $\mathrm{AKI}$ among major burns was 0.11 per 100,000 people per year during the study period. (See selection of patients in Figure 1.) For the majority (14 of 17) of the excluded patients who died within 2 days, active burn care was withheld or withdrawn because of extensive and deep burns, and 8 of the 14 patients were more than 70 years old. They were older (71.1 years, $95 \% \mathrm{Cl} 63.8$ to 78.5 ) and had more extensive burns $(58.6 \%$ TBSA $\%, 95 \% \mathrm{Cl} 46.4 \%$ to $70.8 \%)$ than the 127 patients in the study group $(P<0.001)$. Three patients had renal failure before active treatment was withdrawn, but no renal replacement therapy was started. Eight patients with superficial burns $(25.1 \%$ TBSA\%, 95\% Cl $20.3 \%$ to $29.9 \%$ ) that did not require operation and who were inpatients for only a short period (5.3 days, $95 \% \mathrm{Cl} 0.68$ to 9.82) were also excluded.

A total of 127 patients remained in this study (Table 2), of whom 24\% developed AKI (11.8\% Risk, 7.9\% Injury, and $4.7 \%$ Failure) and 3\% required renal replacement therapy (Table 3). Overall mortality was 14\%. Twenty-nine of the 31 patients who developed AKI had flame burns. One of the two remaining patients had an electrical burn, and one had a chemical hot scald burn (industrial); both were classified as Risk. Seven of the 31 patients (1 classified as Risk, 2 as Injury, and 4 as Failure) had previous histories of hypertension, but none had a documented history of renal dysfunction. One of the patients who was classified as Risk had a previous history of taking lithium. No others had histories of diagnoses affecting the kidney before the burn.

Half of the patients who developed AKI (55\%, 17 of 31) reached the level for Risk within the first 7 days, and $81 \%$ (25 of 31 ) within 14 days. The progress time from Risk to maxi- 
Table 2

Characteristics, baseline, and outcome of patients studied who were classified by RIFLE

\begin{tabular}{|c|c|c|c|c|}
\hline & No AKI $(n=96)$ & $\operatorname{AKI}(n=31)$ & $P$ value & Adjusted \\
\hline Age, years & 35.9 (31.8 to 40.1$)$ & $55.1(47.4$ to 62.7$)$ & $<0.001$ & \\
\hline Total body surface area, percentage burned & 35.8 (33.0 to 38.5$)$ & 47.2 (38.3 to 56.1$)$ & 0.001 & \\
\hline Full thickness burns, percentage & $13.6(10.9$ to 16.4$)$ & 32.0 (24.0 to 40.0$)$ & $<0.001$ & \\
\hline Gender, female/male & $22 / 74$ & $10 / 21$ & 0.30 & \\
\hline Mortality & $7(7.3 \%)$ & $11(35.5 \%)$ & $<0.001$ & \\
\hline Multiple organ failure & $3(3.1 \%)$ & $24(77.4 \%)$ & $<0.001$ & \\
\hline Mechanical ventilation & $51(53.1 \%)$ & $30(96.8 \%)$ & $<0.001$ & \\
\hline Length of stay for survivors, days & 39.9 (32.5 to 47.3$)$ & 67.3 (46.0 to 88.6$)$ & 0.004 & \\
\hline \multicolumn{5}{|l|}{ Baseline laboratory variables } \\
\hline Plasma creatinine, $\mu \mathrm{mol} / \mathrm{L}$ & $81.3(76.4$ to 86.1$)$ & 82.3 (72.0 to 92.5$)$ & 0.85 & 0.87 \\
\hline Platelet count, $\times 10^{9} / \mathrm{L}$ & 238 (218 to 259$)$ & 278 (231 to 326$)$ & 0.08 & 0.14 \\
\hline Plasma bilirubin, $\mu \mathrm{mol} / \mathrm{L}$ & 18.9 (15.5 to 22.3$)$ & 24.0 (17.3 to 30.6$)$ & 0.13 & 0.21 \\
\hline \multicolumn{5}{|l|}{ Worst laboratory value during the first week } \\
\hline Lowest platelet count, $\times 10^{9} / \mathrm{L}$ & 120 (106 to 133$)$ & 68 (48 to 87 ) & $<0.001$ & 0.001 \\
\hline Plasma bilirubin, $\mu \mathrm{mol} / \mathrm{L}$ & 19.9 (16.7 to 23.0$)$ & $37.4(26.1$ to 48.6$)$ & $<0.001$ & 0.001 \\
\hline
\end{tabular}

Table 3

Characteristics, baseline, and outcome of the patients who developed acute kidney injury classified by RIFLE $(n=31)$

\begin{tabular}{|c|c|c|c|c|}
\hline & Risk $(n=15)$ & Injury $(n=10)$ & Failure $(n=6)$ & $P$ value \\
\hline Age, years & 47.7 (36.1 to 59.2$)$ & $56.9(42.7$ to 71.1$)$ & 70.5 (55.1 to 85.9$)$ & 0.07 \\
\hline Total body surface area, percentage burned & 45.6 (32.5 to 58.7$)$ & 56.5 (37.1 to 75.9$)$ & $35.8(17.8$ to 53.9$)$ & 0.25 \\
\hline Full thickness burns, percentage & 32.4 (19.9 to 44.8$)$ & $36.0(17.2$ to 54.9$)$ & 24.3 (14.4 to 34.3$)$ & 0.60 \\
\hline Gender, female/male & $6 / 9$ & $2 / 8$ & $2 / 4$ & 0.58 \\
\hline Mortality & 2 & 4 & 5 & 0.01 \\
\hline Dialysis & - & - & 4 & \\
\hline Recovery & 13 & $5^{a}$ & $2^{b}$ & 0.04 \\
\hline Multiple organ failure & 9 & 9 & 6 & 0.07 \\
\hline Lowest mean arterial pressure, $\mathrm{mm} \mathrm{Hg}$ & $56.0(53.2$ to 58.8$)$ & $62.2(56.1$ to 68.3$)$ & $57.2(52.4$ to 61.9$)$ & 0.06 \\
\hline Adrenergic drugs on days $1-3^{c}$ & 11 & 5 & 5 & 0.31 \\
\hline Mechanical ventilation & 15 & 9 & 6 & $0.34^{d}$ \\
\hline Length of stay for survivors, days & 69.2 (40.0 to 98.3 ) & $66.8(17.2$ to 116.4$)$ & 46 & 0.90 \\
\hline
\end{tabular}


mum RIFLE class was 5.2 days ( $95 \% \mathrm{Cl} 2.0$ to 8.5$)$ among the 16 patients who reached Injury and Failure, whereas the time from baseline to Risk was 9.4 days $(95 \% \mathrm{Cl} 5.9$ to 13.0$)(P=$ 0.095). Early $A K I$ was arbitrarily defined as when creatinine reached the level for Risk within the first 7 days, late AKI between days 8 and 60 (Table 4). We found a more than twofold higher risk for younger patients (risk ratio 2.35) and for patients with extensive deep burns (risk ratio 2.25) to develop AKI early (Table 5).

\section{Recovery and mortality}

Renal function recovered completely during the time of admission to the burn unit among all patients who survived except for two: the dialysed patient who survived, whose renal function partially recovered, and one patient classified as Injury, who was transferred to another hospital before recovery. Mortality increased with increasing AKI class. The 11 patients having $\mathrm{AKI}$ and who died all had multiple organ failure. Among the four patients who required renal replacement therapy, plasma creatinine was within the reference range during the first day after injury in all cases but one, whose plasma creatinine was $126 \mu \mathrm{mol} / \mathrm{L}$. All four had multiple organ failure before dialysis, and two had sepsis before. The remaining two already had SIRS on admission but no sepsis during their stay. The treatment with dialysis started on days 5 to 19 (10 to 15 days of treatment over 13 to 21 days), and the week-maximum plasma creatinine concentration and plasma urea before starting were $392.0 \mu \mathrm{mol} / \mathrm{L}$ (208.5 to 575.5 ) and $28.9 \mathrm{mmol} / \mathrm{L}$ (15.2 to 42.7 ), respectively. Two of the patients were oliguric the day before, and the patient with early dialysis (day 5) was oliguric 4 days before. Three of the dialysed patients died.

\section{Factors of importance in the development of acute kidney injury}

Predisposing factors

Age, TBSA\%, and extent of FTBs were greater among the patients who developed AKI (Table 2). We found no significant difference in these variables between the RIFLE classes when we analysed the AKI-classified patients, even if there was a trend toward increasing age (Table 3 ).

\section{Sepsis}

The patients who developed AKI $(n=31)$ all fulfilled the criteria for SIRS on day 1, and 87\% (27 of 31) developed sepsis, of whom 19 were classified as severe sepsis or septic shock. Sepsis developed within a week before the first sign of renal dysfunction (reaching the level of Risk) in 48\%, and most of these records of sepsis were classified as severe. Sepsis cumulative onset is presented in Figure 2. Sepsis also developed without inducing further renal dysfunction during the renal recovery period among seven patients.

\section{Potentially nephrotoxic exposures}

Twelve of the AKI-classified patients (39\%) were treated with potentially nephrotoxic antibiotics and five of them required more than one. The total number of treatment periods among them was 25 . In 6 of the 12 patients, an increase in the plasma creatinine concentration was seen after starting one treatment (starting day ranged from 3 to 92 after the burn) and severe sepsis was present on all of these occasions.

Seven of the patients who did not develop AKI were exposed to intravenous contrast (CT scans). One of the patients who were classified as Failure was exposed on day 2 in parallel with increasing plasma creatinine concentration, and 2 patients classified as Risk were exposed 6 and 19 days,

Table 4

Early and late acute kidney injury: characteristics, multiple organ failure, and sepsis

\begin{tabular}{|c|c|c|c|}
\hline & Early AKI $(n=17)$ & Late AKI $(n=14)$ & $P$ value \\
\hline Age, years & $48.9(39.7$ to 58.1$)$ & 62.6 (49.7 to 75.5$)$ & 0.07 \\
\hline Total body surface area, percentage burned & $53.3(41.0$ to 65.6$)$ & 39.8 (26.4 to 53.2 ) & 0.13 \\
\hline Full thickness burns, percentage & $39.4(28.1$ to 50.7$)$ & $23.0(12.2$ to 33.8$)$ & 0.04 \\
\hline Multiple organ failure & 14 & 10 & 0.47 \\
\hline Sepsis & 15 & 12 & 0.83 \\
\hline Lowest value of MAP for days $1-3, \mathrm{~mm} \mathrm{Hg}$ & 57.5 (54.9 to 60.2$)$ & 59.1 (54.3 to 63.9$)$ & 0.53 \\
\hline Plasma myoglobin for days $1-2, \mu \mathrm{g} / \mathrm{L}$ & $1,167(-484$ to 2,820$)$ & 220 (103 to 337$)$ & 0.24 \\
\hline Mechanical ventilation & 17 & 13 & - \\
\hline Length of stay, days & 45.7 (27.8 to 63.6$)$ & $60.6(27.9$ to 93.4$)$ & 0.37 \\
\hline
\end{tabular}

Data are mean (95\% confidence interval) or number of patients. Early acute kidney injury (AKI) is defined as when creatinine reached the level for Risk within the first 7 days; late AKI occurred between days 8 and 60 . Multiple organ failure is defined as 3 to 4 score points in two or more organ dimensions of the sequential organ failure assessment score. (Contingency table, Pearson chi-square test for categorical variables, and Student $t$ test for continuous data.) MAP, mean arterial pressure. 
Table 5

Early and late acute kidney injury: odds ratio for characteristics, multiple organ failure, and sepsis

\begin{tabular}{|c|c|c|c|c|}
\hline & Early AKI & Late AKI & & \\
\hline Failure/lnjury/Risk (all patients) & $3 / 5 / 9(17)$ & $3 / 5 / 6(14)$ & $95 \% \mathrm{Cl}$ & OR \\
\hline Age of $<60 / \geq 60$ years & $13 / 4$ & $5 / 9$ & 1.22 to 28.0 & 5.85 \\
\hline TBSA $\%$ of $\geq 50 \% /<50 \%$ & $10 / 7$ & $3 / 11$ & 1.06 to 26.0 & 5.20 \\
\hline FTB $\%$ of $\geq 25 \% /<25 \%$ & $12 / 5$ & $4 / 10$ & 1.26 to 28.5 & 6.00 \\
\hline Gender, male/female & $12 / 5$ & $9 / 5$ & 0.29 to 6.04 & 1.33 \\
\hline Mortality (non-survivors) & 6 & 5 & 0.22 to 4.30 & 0.98 \\
\hline Dialysis & 3 & 1 & 0.26 to 30.27 & 2.79 \\
\hline MOF before AKI & 13 & 10 & 0.26 to 6.52 & 1.30 \\
\hline Sepsis before AKI & 11 & $8^{a}$ & 0.32 to 5.88 & 1.38 \\
\hline MOF and sepsis both before AKI & 8 & 8 & 0.16 to 2.77 & 0.67 \\
\hline MAP episode $<60 \mathrm{~mm} \mathrm{Hg}$ on days $1-3$ & 10 & 9 & 0.18 to 3.41 & 0.79 \\
\hline Adrenergic drugs on days $1-3$ & 14 & 7 & 0.91 to 23.79 & 4.67 \\
\hline
\end{tabular}

Data are number of patients. Early acute kidney injury (AKI) is defined as when creatinine reached the level for Risk within the first 7 days; late AKI occurred between days 8 and 60 . Multiple organ failure (MOF) is defined as 3 to 4 score points in two or more organ dimensions of the sequential organ failure assessment score. Onset on the same day as AKI is included in the onset before category. aTwo more patients had sepsis before $\mathrm{AKI}$, but there were 11 and 48 days, respectively, between their sepsis recordings and AKI onset, which was on days 25 and 60 . Continuous variables were arbitrarily categorised: cutoff for age was 60 years, full thickness burn percentage (FTB\%) was $25 \%$, and percentage burned of total body surface area (TBSA\%) was $50 \%$. Cl, confidence interval; MAP, mean arterial pressure; OR, odds ratio.

respectively, before the increase. Plasma myoglobin (highest value days 1 to 2$)$ values were $1,606 \mu \mathrm{g} / \mathrm{L}(95 \% \mathrm{Cl} 677$ to $2,534)$ in the non-AKI group and $712 \mu \mathrm{g} / \mathrm{L}(95 \% \mathrm{Cl}-111$ to $1,537)$ among the patients who developed AKI $(P=0.22)$.

\section{Relation to other organs}

Organ dysfunction in general was most pronounced during the first weeks after injury (Figure 3), and outcome depended on the number and degree of failing organs. Maximum SOFA total was 14.1 (95\% Cl 12.5 to 15.6) among non-survivors with AKI compared with 10.2 (95\% Cl 9.0 to 11.4 ) among survivors with $\mathrm{AKI}(P<0.001$, adjusted for age and TBSA $\% P=$ $0.001)$. But when each dimension was analysed among the 31 patients with $\mathrm{AKI}$, only the renal and cardiovascular dimensions were higher among the patients who died (maximum renal dimension was 2.7 (95\% Cl 1.9 to 3.6$)$ and the cardiovascular dimension was $3.6(95 \% \mathrm{Cl} 3.3$ to 4.0$)$ among nonsurvivors compared with $1.2(95 \% \mathrm{Cl} 0.7$ to 1.6$)$ and 2.4 (95\% Cl 2.1 to 2.7 ) among survivors $(P<0.001$ for both dimensions, adjusted for age and TBSA $\% P=0.002$ for renal dimension, and $P<0.001$ for cardiovascular dimension)). Pulmonary dysfunction preceded $\mathrm{AKI}$, and $97 \%$ (30 of 31) required mechanical ventilation and $61 \%$ (19 of 31 ) had a $\mathrm{PaO}_{2} / \mathrm{FiO}_{2}$ ratio reduced to less than $200 \mathrm{~mm} \mathrm{Hg}$ (scoring 3 to 4 points on the SOFA respiratory dimension) within the first 3 days.

\section{Discussion}

This is, to our knowledge, the first study to assess AKI in burns using a prospective protocol with the RIFLE classification as well as the assessment of organ failure, SIRS, and sepsis using conventional criteria and definitions. The study adds new and important information about several topics in a com-

\section{Figure 2}

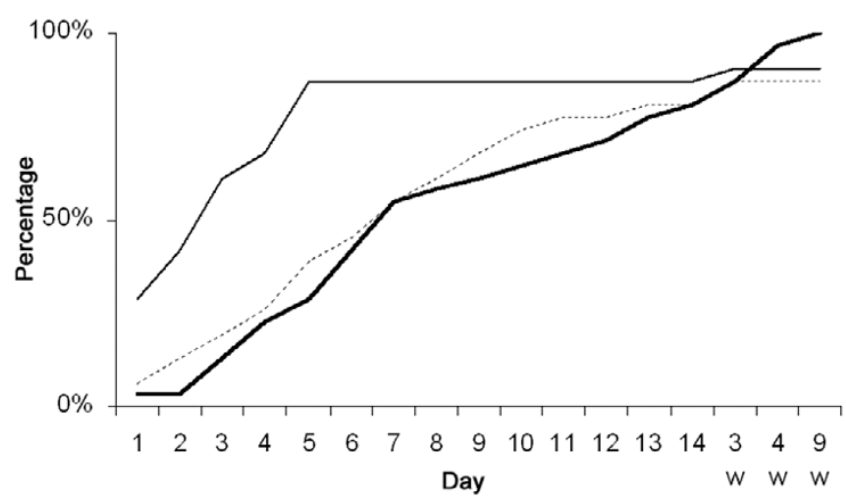

Day of onset of renal dysfunction, respiratory dysfunction, and sepsis. Cumulative percentage of the patients who developed renal dysfunction showing when their plasma creatinine concentration exceeded at least $1.5 \times$ baseline $(n=31$, thick line) and who developed severe respiratory dysfunction (sequential organ failure assessment score of 3 to $4=\mathrm{PaO}_{2} / \mathrm{FiO}_{2}$ [arterial partial pressure of oxygen/fraction of inspired oxygen] below $200 \mathrm{~mm} \mathrm{Hg}, \mathrm{n}=28$, thin line) and sepsis ( $n=27$, dotted line). $X$-axis shows the first 14 days after injury. The remaining times are weeks. 
Figure 3

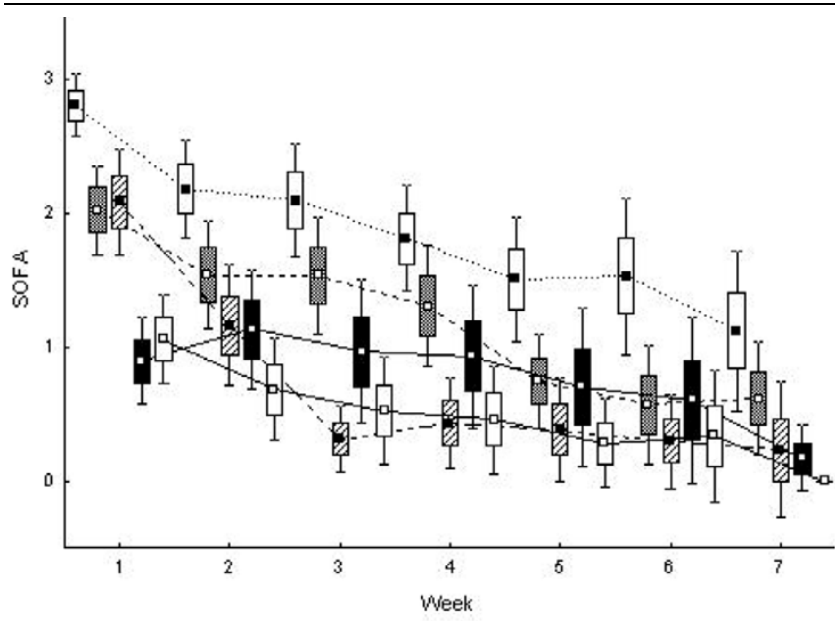

Maximum sequential organ failure assessment (SOFA) score among the patients who developed renal dysfunction $(n=31)$. SOFA score is calculated on the maximum value for each of five organ dimensions weekly during the first 7 weeks after injury: maximum SOFA respiratory dimension (closed square, open box), cardiovascular dimension (open square, shaded box), coagulation dimension (closed square, diagonal pattern in the box), renal dimension (open square, closed box), and hepatic dimension (open square, open box). Squares indicate the mean, the box indicates standard error, and whiskers indicate $95 \%$ confidence interval.

prehensive way. It shows that $\mathrm{AKI}$ is common, that AKI corresponds to about a quarter of those with a TBSA\% of more than 20\%, and that survivors can recover from AKI. AKI also develops soon after injury and is closely paralleled by dysfunction of other organs. We found that AKI was preceded by lung dysfunction in almost all of the cases, as has previously been claimed by Sheridan and colleagues [14]. Only the cardiovascular dysfunction (maximum SOFA) and AKI were associated with mortality. The relation with sepsis was not as incontestable as is usually claimed since sepsis was not always followed by renal dysfunction.

Renal dysfunction seems to follow a course similar to that of other dysfunctioning or failing organs, more so as the time delay between different organ dysfunctions can be considered (at least to some extent) as being marker-specific rather than organ-specific. The actual impact on the kidneys is likely to happen before the increase in plasma creatinine concentration is detected. For example, Kang and colleagues [35] found raised 24-hour urinary $N$-acetyl-beta-D-glucosaminidase activity (a marker of proximal tubular dysfunction or damage) on day 1 among the 12 burned patients whom they studied $(30 \%$ TBSA\%). It was almost doubled on day 1 , continued to increase, and peaked on day 7 .

\section{Incidence and occurrence}

We found AKI to be common, with an incidence of about a quarter of major burns, which is similar to that reported in a recent paper by Coca and colleagues [19] and slightly less than reported in a letter from Lopes and colleagues [20]. Median time to reaching respective RIFLE class was 10 days in our AKI group, which is the same as that reported by Lopes and colleagues [20]. However, unlike Coca and colleagues [19], we did not find a difference in the time of occurrence between RIFLE classes. The requirement of renal replacement therapy among patients with burns who require intensive care seems not to differ from that of general intensive care units (ICUs). The percentage of renal replacement therapy in our study $(3.1 \%)$ is close to that reported in ICU patients (Hoste and colleagues [2] 4.1\%, Bell and colleagues [36] 2.5\%, Uchino and colleagues [4] 4.3\%, and Dalfino and colleagues [37] $8.1 \%$ ) and in most studies of patients with burns (Table 1).

\section{Recovery or mortality}

All of the surviving patients in the present study recovered renal function (defined according to RIFLE). This is consistent with findings reported by several others $[8,10,12,15]$. In a multicentre long-term follow-up of patients in intensive care who had required renal replacement while they were in hospital, $3.4 \%$ (34 of 998) of those who survived developed late endstage kidney disease, as identified from a nationwide register for chronic renal disease [38].

Mortality increased with increasing RIFLE class, and in the studies of Coca and colleagues [19] and Lopes and colleagues [20] mortality rates were $60 \%$ and $75 \%$, respectively, in the Failure class, whereas the rate was 5 of 6 in our study. Overall mortality rates were $14 \%$ in our study, $13 \%$ in the study of Coca and colleagues, and $18 \%$ in the study of Lopes and colleagues. ICU mortality among RIFLE-Failure-classified patients seems to be somewhat lower than among burned patients who were classified as Failure. Hoste and colleagues [2] reported $26 \%$ mortality in the Failure class from a study of critically ill patients, and Lopes and colleagues [39] found a $55 \%$ mortality in the Failure class among patients with sepsis.

\section{Pathophysiology of renal dysfunction in burns}

The reason for AKI among patients with major burns may be multifactorial. We found that the acute increase in plasma creatinine concentration was preceded by the initial inflammatory response (SIRS) and pulmonary dysfunction. Pulmonary dysfunction after trauma has been suggested to promote pathogenic inflammation and the development of multiple organ failure, including renal failure [40]. In our recent study of acute respiratory dysfunction in patients with major burns, we noted that acute respiratory distress syndrome occurs soon after the burn - usually within 3 days - and that renal dysfunction was more common among the patients with the most severe respiratory dysfunction [32]. This, together with the early onset of organ dysfunction, including renal dysfunction, suggests that it is the burn and resuscitation rather than infective complications that are responsible for the failing organs. 


\section{Sepsis}

Sepsis occurred in $87 \%$ of the AKI group, which is of the same magnitude as reported in previous burn studies [11,19]. We found that severe sepsis was associated with AKI, even if not all episodes of severe sepsis caused renal dysfunction. In four of six cases in which AKI was of latest onset (days 18 to 60 after burn), it was not preceded by sepsis, contradicting the idea that $\mathrm{AKI}$ of late onset was associated mainly with sepsis $[15,17]$. Chrysopoulo and colleagues [16] found that AKI among survivors was not the result of sepsis since it preceded sepsis in their study. Another interesting finding is that we found sepsis during the renal recovery period without inducing further renal dysfunction, which has not been previously reported. This finding indicates that at least some of the timeassociated episodes of sepsis and renal dysfunction may also be just time-related rather than the result of cause and effect - a possibility that is usually not discussed in studies of burned patients where $\mathrm{AKI}$ is considered to be strongly associated with sepsis $[10,12,15,17,19]$.

\section{Predisposing factors}

We found age, TBSA $\%$, and FTB $\%$ to be predisposing factors for AKI but were unable to show the corresponding relation for severity of AKI, most probably because of a lack of power. Coca and colleagues [19] also found older patients in the AKI group, whereas others (for example, Holm and colleagues [11] and $\mathrm{Kim}$ and colleagues [17]) found a higher TBSA $\%$ in the AKI group, but not advanced age. In the study by Kim and colleagues, mean TBSA\% was unusually high in the AKI group $(80 \%)$ whereas age was relatively young (42 years).

\section{Method}

It is important to evaluate the characteristics of patients with burns. Effects are seen on incidence of organ dysfunction and on outcome by the number of patients who have treatment withheld or withdrawn. In different studies, the size of this group has been in the range of $5 \%$ to $11 \%[6,14]$. In a number of studies, no such data are presented [8-13,15-17,19-21]. We have excluded all patients who died within the first 48 hours, including cases of initial withholding or withdrawal of treatment. The exclusion criteria of 'short hospital stay' has been used by others [7].

The potential selection bias from excluding the patients with the worst (death within 2 days) and the best (short duration of stay) outcomes has probably influenced the incidence of AKI in this study. The finding that young age is a risk factor for early $\mathrm{AKI}$ can also be explained by this selection bias since older patients with extensive burns more often have a lethal outcome.

The fluid resuscitation early after burn is a problem when using the RIFLE criteria and not having a true baseline plasma creatinine concentration taken. The initially low concentrations in plasma, however, should be of the same magnitude among burn patients as a group, reflecting a physiological response to the burn and the fluid resuscitation. Hence, using the RIFLE classification may still be reliable for comparing incidences of acute renal dysfunction between studies of burn patients. The same 'misclassification' problem is, however, likely to occur among other patient groups who are subjected to aggressive fluid resuscitation (ICU patients with major trauma or those with severe sepsis) and whose true baseline may be unknown. Whether the RIFLE should be modified for these circumstances needs to be further examined.

\section{Conclusion}

$\mathrm{AKI}$ is common, develops soon after the burn, and is paralleled by multiple organ dysfunction or failure, which also appear early. Among the dysfunctioning organs, cardiovascular dysfunction (SOFA) together with AKI was associated with a higher mortality. The prognosis for minor dysfunction remains good and survivors recover from AKI, whereas renal failure still carries a high mortality. Pulmonary dysfunction preceded AKI and 30 of the 31 patients with $\mathrm{AKI}$ required mechanical ventilation whereas only half of those with no AKI required mechanical ventilation. Sepsis was not always followed by AKI.

\section{Key messages}

- Acute kidney injury (AKI) is common, develops soon after the burn, and is paralleled by multiple organ dysfunction.

- Cardiovascular dysfunction together with AKI was associated with a higher mortality.

- The prognosis for minor dysfunction remains good and survivors recover from AKI, whereas renal failure still carries a high mortality.

\section{Competing interests}

The authors declare that they have no competing interests.

\section{Authors' contributions}

IS participated in the design of the study, acquired the data and performed the statistical analysis, participated in the interpretation of data, and drafted the manuscript. ZB critically revised the study. FS had the original idea and participated in the design of the study, interpretation of data, and drafting of the manuscript. All authors read and approved the final manuscript.

\section{Acknowledgements}

We thank Olle Ericsson, Department of Applied Statistics, Linköping University, Linköping, Sweden, for statistical advice and Mary Evans, consulting technical editor, for revising the English text.

\section{References}

1. de Mendonca A, Vincent JL, Suter PM, Moreno R, Dearden NM, Antonelli M, Takala J, Sprung C, Cantraine F: Acute renal failure in the ICU: risk factors and outcome evaluated by the SOFA score. Intensive Care Med 2000, 26:915-921. 
2. Hoste EA, Clermont G, Kersten A, Venkataraman R, Angus DC, De Bacquer D, Kellum JA: RIFLE criteria for acute kidney injury are associated with hospital mortality in critically ill patients: a cohort analysis. Crit Care 2006, 10:R73.

3. Ala-Kokko T, Ohtonen P, Laurila J, Martikainen M, Kaukoranta P: Development of renal failure during the initial $24 \mathrm{~h}$ of intensive care unit stay correlates with hospital mortality in trauma patients. Acta Anaesthesiol Scand 2006, 50:828-832.

4. Uchino S, Kellum JA, Bellomo R, Doig GS, Morimatsu H, Morgera S, Schetz M, Tan I, Bouman C, Macedo E, Gibney N, Tolwani A, Ronco C: Acute renal failure in critically ill patients: a multinational, multicenter study. JAMA 2005, 294:813-818.

5. Miller SF, Bessey PQ, Schurr MJ, Browning SM, Jeng JC, Caruso DM, Gomez M, Latenser BA, Lentz CW, Saffle JR, Kagan RJ, Purdue GF, Krichbaum JA: National Burn Repository 2005: a tenyear review. J Burn Care Res 2006, 27:411-436.

6. Cumming J, Purdue GF, Hunt JL, O'Keefe GE: Objective estimates of the incidence and consequences of multiple organ dysfunction and sepsis after burn trauma. J Trauma 2001, 50:510-515.

7. Saffle JR, Sullivan JJ, Tuohig GM, Larson CM: Multiple organ failure in patients with thermal injury. Crit Care Med 1993, 21:1673-1683

8. Davies DM, Pusey CD, Rainford DJ, Brown JM, Bennett JP: Acute renal failure in burns. Scand J Plast Reconstr Surg 1979, 13:189-192.

9. Davies MP, Evans J, McGonigle RJ: The dialysis debate: acute renal failure in burns patients. Burns 1994, 20:71-73.

10. Leblanc $M$, Thibeault $Y$, Querin S: Continuous haemofiltration and haemodiafiltration for acute renal failure in severely burned patients. Burns 1997, 23:160-165.

11. Holm C, Horbrand F, von Donnersmarck GH, Muhlbauer W: Acute renal failure in severely burned patients. Burns 1999, 25:171-178.

12. Tremblay R, Ethier J, Querin S, Beroniade V, Falardeau P, Leblanc $\mathrm{M}$ : Veno-venous continuous renal replacement therapy for burned patients with acute renal failure. Burns 2000, 26:638-643.

13. Schiavon M, Di Landro D, Baldo M, De Silvestro G, Chiarelli A: A study of renal damage in seriously burned patients. Burns Incl Therm Inj 1988, 14:107-112.

14. Sheridan RL, Ryan CM, Yin LM, Hurley J, Tompkins RG: Death in the burn unit: sterile multiple organ failure. Burns 1998, 24:307-311.

15. Jeschke MG, Barrow RE, Wolf SE, Herndon DN: Mortality in burned children with acute renal failure. Arch Surg 1998, 133:752-756

16. Chrysopoulo MT, Jeschke MG, Dziewulski P, Barrow RE, Herndon DN: Acute renal dysfunction in severely burned adults. J Trauma 1999, 46:141-144.

17. Kim GH, Oh KH, Yoon JW, Koo JW, Kim HJ, Chae DW, Noh JW, Kim JH, Park YK: Impact of burn size and initial serum albumin level on acute renal failure occurring in major burn. $A m J$ Nephrol 2003, 23:55-60.

18. Cooper AB, Cohn SM, Zhang HS, Hanna K, Stewart TE, Slutsky AS: Five percent albumin for adult burn shock resuscitation: lack of effect on daily multiple organ dysfunction score. Transfusion 2006, 46:80-89.

19. Coca SG, Bauling P, Schifftner T, Howard CS, Teitelbaum I, Parikh CR: Contribution of acute kidney injury toward morbidity and mortality in burns: a contemporary analysis. Am J Kidney Dis 2007, 49:517-523.

20. Lopes JA, Jorge S, Neves FC, Caneira M, da Costa AG, Ferreira AC, Prata MM: An assessment of the RIFLE criteria for acute renal failure in severely burned patients. Nephrol Dial Transplant 2007, 22:285.

21. Lopes JA, Jorge S, Neves FC, Costa AG, Prata MM, Caneira M, Ferreira AC: Acute renal failure in severely burned patients. Resuscitation 2007, 73:318.

22. Mustonen KM, Vuola J: Acute Renal Failure in Intensive Care Burn Patients (ARF in Burn Patients). J Burn Care Res 2008, 29:227-237.

23. Bellomo R, Ronco C, Kellum JA, Mehta RL, Palevsky P: Acute renal failure - definition, outcome measures, animal models, fluid therapy and information technology needs: the Second International Consensus Conference of the Acute Dialysis Quality Initiative (ADQI) Group. Crit Care 2004, 8:R204.
24. Fitzwater J, Purdue GF, Hunt JL, O'Keefe GE: The risk factors and time course of sepsis and organ dysfunction after burn trauma. J Trauma 2003, 54:959-966.

25. Vincent JL, Moreno R, Takala J, Willatts S, De Mendonca A, Bruining $\mathrm{H}$, Reinhart CK, Suter PM, Thijs LG: The SOFA (Sepsisrelated Organ Failure Assessment) score to describe organ dysfunction/failure. On behalf of the Working Group on Sepsis-Related Problems of the European Society of Intensive Care Medicine. Intensive Care Med 1996, 22:707-710.

26. Vincent JL, de Mendonca A, Cantraine F, Moreno R, Takala J, Suter PM, Sprung CL, Colardyn F, Blecher S: Use of the SOFA score to assess the incidence of organ dysfunction/failure in intensive care units: results of a multicenter, prospective study. Working group on 'sepsis-related problems' of the European Society of Intensive Care Medicine. Crit Care Med 1998, 26:1793-1800.

27. Moreno R, Vincent JL, Matos R, Mendonca A, Cantraine F, Thijs L, Takala J, Sprung C, Antonelli M, Bruining H, Willatts S: The use of maximum SOFA score to quantify organ dysfunction/failure in intensive care. Results of a prospective, multicentre study. Working Group on Sepsis related Problems of the ESICM. Intensive Care Med 1999, 25:686-696.

28. Peres Bota D, Melot C, Lopes Ferreira F, Nguyen Ba V, Vincent JL: The Multiple Organ Dysfunction Score (MODS) versus the Sequential Organ Failure Assessment (SOFA) score in outcome prediction. Intensive Care Med 2002, 28:1619-1624.

29. Baxter CR: Fluid volume and electrolyte changes of the early postburn period. Clin Plast Surg 1974, 1:693-703.

30. Bak Z, Sjoberg F, Eriksson O, Steinvall I, Janerot-Sjoberg B: Hemodynamic changes during resuscitation after burns using the Parkland formula. J Trauma in press.

31. Samuelsson A Steinvall I Sjoberg F: Microdialysis shows metabolic effects in skin during fluid resuscitation in burn-injured patients. Crit Care 2006, 10:R172.

32. Steinvall I, Bak Z, Sjoberg F: Acute respiratory distress syndrome is as important as inhalation injury for the development of respiratory dysfunction in major burns. Burns 2008, 34:441-451.

33. American College of Chest Physicians/Society of Critical Care Medicine Consensus Conference: definitions for sepsis and organ failure and guidelines for the use of innovative therapies in sepsis. Crit Care Med 1992, 20:864-874.

34. Sjoberg F, Danielsson P, Andersson L, Steinwall I, Zdolsek J Ostrup L, Monafo W: Utility of an intervention scoring system in documenting effects of changes in burn treatment. Burns 2000, 26:553-559.

35. Kang HK, Kim DK, Lee BH, Om AS, Hong JH, Koh HC, Lee CH, Shin IC, Kang JS: Urinary N-acetyl-beta-D-glucosaminidase and malondialdehyde as a markers of renal damage in burned patients. J Korean Med Sci 2001, 16:598-602.

36. Bell M, Liljestam E, Granath F, Fryckstedt J, Ekbom A, Martling CR: Optimal follow-up time after continuous renal replacement therapy in actual renal failure patients stratified with the RIFLE criteria. Nephrol Dial Transplant 2005, 20:354-360.

37. Dalfino L, Tullo L, Donadio I, Malcangi V, Brienza N: Intra-abdominal hypertensionand acute renal failurein critically ill patients. Intensive Care Med 2008, 34:707-713.

38. Bell M, Granath F, Schon S, Ekbom A, Martling CR: Continuous renal replacement therapy is associated with less chronic renal failure than intermittent haemodialysis after acute renal failure. Intensive Care Med 2007, 33:773-780.

39. Lopes JA, Jorge S, Resina C, Santos C, Pereira A, Neves J, Antunes F, Prata MM: Prognostic utility of RIFLE for acute renal failure in patients with sepsis. Crit Care 2007, 11:408.

40. Ciesla DJ, Moore EE, Johnson JL, Burch JM, Cothren CC, Sauaia $A$ : The role of the lung in postinjury multiple organ failure. Surgery 2005, 138:749-757. discussion 757-748. 